\title{
Prospective Memory and Traumatic Brain Injury: A Review
}

\author{
David Shum \\ Griffith University, Australia \\ Jenny Fleming \\ The University of Queensland and Princess Alexandra Hospital, Australia \\ Kerryn Neulinger \\ Griffith University, Australia
}

\begin{abstract}
$\mathrm{T}$ his article aimed to review the assessment and treatment of prospective memory impairment in individuals with traumatic brain injury. The three assessment techniques reviewed included questionnaires, psychological tests, and experimental procedures. Because interest in this area is relatively new, not many assessment techniques have been specifically developed to assess the various constructs of prospective memory. Of these, most lack a firm theoretical basis, adequate norms, and strong psychometric properties. Rehabilitative techniques, based on remedial and compensatory approaches, were then evaluated. Intervention methods that show promise include a prospective memory training approach, diary or memory notebook use, and electronic aids. Nevertheless, there is a need for further controlled trials with larger sample sizes to more thoroughly evaluate these methods. Self-awareness of memory impairment and generalisation of gains from treatment are another two issues identified as important for assessing and treating prospective memory impairment.
\end{abstract}

Memory impairment is a symptom commonly reported by individuals with traumatic brain injury (TBI) and their significant others (Goldstein \& Levin, 1995; Richardson, 2000). Because memory is one of the most important cognitive processes, and memory difficulties after TBI are usually long lasting, this type of impairment has been found to be debilitating and difficult to treat (Levin, 1991; Williamson, Scott \& Adams, 1996). In the literature, there exists a large number of studies that have examined the nature and effects of memory impairment following TBI (e.g., Geffen, Butterworth, Forrester \& Geffen, 1994; Haut, Petros, Frank \& Lamberty, 1990; Levin \& Goldstein, 1986; Mangels, Craik, Levine, Schwartz \& Stuss, 2000; Millis \& Dijkers, 1993; Reid \& Kelly, 1993; Shum, Harris \& O'Gorman, 2000; Shum, Sweeper \& Murray, 1996; Vanderploeg, Crowell \& Curtiss, 2001).
Most, if not all, of these studies were designed to study an individual's ability to remember past events or recall previously presented information, a type of memory commonly referred to as retrospective memory (Dalla Barba, 1993). In addition, most techniques and procedures in the rehabilitation literature were developed to treat this type of memory impairment (Butters, Soety \& Glisky, 1996; Ponsford, 1995; Tate, 1997; Wilson, 1992, 1999).

While retrospective memory is important for individuals with TBI, many day-to-day activities of these individuals also involve the ability to remember to perform an action in the future (e.g., remembering to buy a loaf of bread on the way home, remembering to pay bills, remembering to turn off an electrical appliance, remembering to take medication, and remembering to turn up for an appointment at the hospital or the 
rehabilitation centre). This ability is referred to as prospective memory and it has been defined as "the process or skills required to support the fulfillment of an intention to perform a specific action in the future" (Ellis \& Kvavilashvili, 2000 , p. 1). Usually the intention is formed before the required time of action and cannot be put into effect at the time of its formation because of various reasons (e.g., logistic, social, geographical, etc.). Moreover, unlike retrospective memory, an explicit reminder to carry out the intention is generally absent and one has to interrupt what one is doing to carry out the intention. According to Ellis (1996), there are five phases in a prospective memory task: (a) formation and encoding of intention and action, (b) retention interval, (c) performance interval, (d), initiation and execution of intended action, and (e) evaluation of outcome. As such, prospective memory is more complex than and requires more processes than retrospective memory.

Although prospective memory is a relatively new construct, it has received considerable attention in the ageing literature and most of the theoretical and methodological advances in this area were achieved by studying the ageing population (e.g., Einstein \& McDaniel, 1990; Einstein, McDaniel, Manzi, Cochran, \& Baker, 2000; Einstein, McDaniel, Richardson, Guynn, \& Cunfer, 1995; Maylor, 1998). This construct has also received considerable attention in the TBI literature (Cockburn, 1995; Kinsella et al., 1996; Shum, Valentine \& Cutmore, 1999). This is because of two main reasons. First, in contrast to retrospective memory, prospective memory is concerned with the future and with action. As such, the latter type of memory is considered to be closely related to everyday functioning and independent living. Failure to perform future actions has also been identified by individuals with TBI as a primary concern because it can be both embarrassing and risky (Hannon, Adams, Harrington, Fries-Dias \& Gipson, 1995). A better understanding of the nature and processes underlying this type of memory impairment might enable professionals to assist these individuals to return to work or to living independently in the community. Second, by definition, the construct of prospective memory includes processes such as planning, disruption of an ongoing activity and initiation of an intended action. Because these are commonly regarded as prefrontal-lobe functions and because the prefrontal lobe is a common site of damage after TBI, individuals with TBI are predicted to be prone to having prospective memory impairment (Shum et al., 1999). The study of prospective memory in individuals with TBI will contribute not only to the understanding of the nature of memory problems after TBI but also the functions of the prefrontal lobe.

In this article, we aimed to review prospective memory in individuals with acquired brain injury, specifically, TBI. The two specific purposes of the review were: (a) to evaluate the utility of the procedures or tests designed to assess prospective memory and (b) to evaluate the effectiveness of techniques that had been used to treat or rehabilitate prospective memory impairment. In doing so, we hoped to identify issues that are important for understanding the nature and processes of prospective memory and for improving the assessment and treatment of this type of impairment.

\section{Assessment of Prospective Memory}

Information about people's ability to remember to fulfil a future intention is either obtained from studies that have been theory-driven or from those based on clinical observations. Studies have assessed prospective memory in a number of ways: using questionnaires, psychological tests, and experimental or laboratory procedures.

\section{Questionnaires}

The most frequently used tool for assessing prospective memory is the self-report questionnaire. These questionnaires generally aim to assess a person's memory by asking them to rate their abilities using questions regarding their frequency of forgetting or remembering, how their memory has changed and the type of strategies they use to enhance their memory (Herrmann, 1983). Despite the popularity of self-report measures, there have been few questionnaires developed to specifically assess prospective memory. Rather, this construct is usually embedded in questionnaires measuring everyday memory. This is understandable given the short history of the study of prospective memory.

Several studies have examined everyday memory in people with TBI, using questionnaires which include items about prospective memory. These questionnaires and sample items for assessing prospective memory are summarised in Table 1.

Boake, Freeland, Ringholz, Nance \& Edwards (1995) and Schwartz and McMillan (1989) found correlations between the Rivermead Behavioural Memory Test (RBMT; a psychological test which contains items of prospective memory and will be discussed more fully in the next section) and the 
TABLE 1

\begin{tabular}{|c|c|c|}
\hline Questionnaire & Authors & Sample questions \\
\hline $\begin{array}{l}\text { The Everyday } \\
\text { Memory Questionnaire }\end{array}$ & $\begin{array}{l}\text { Sunderland, Harris } \\
\text { \& Gleave (1984) }\end{array}$ & $\begin{array}{l}\text { "Completely forgetting to do things you said } \\
\text { you would do, and things you planned to do" } \\
\text { "Forgetting to tell somebody something } \\
\text { important. Perhaps forgetting to pass } \\
\text { on a message or remind someone } \\
\text { of something" }\end{array}$ \\
\hline $\begin{array}{l}\text { The Memory } \\
\text { Functioning Questionnaire }\end{array}$ & Gilewski \& Zelinski (1988) & $\begin{array}{l}\text { "How often do these present a problem for you? } \\
\text { 'appointments', 'going to the store and } \\
\text { forgetting what you wanted to buy'" }\end{array}$ \\
\hline $\begin{array}{l}\text { The Subjective } \\
\text { Memory Questionnaire }\end{array}$ & Bennett-Levy \& Powell (1980) & $\begin{array}{l}\text { "How often do you forget whether or not } \\
\text { you have locked up the house, turned off the } \\
\text { fires, etc?" } \\
\text { "How often do you set off to do something, } \\
\text { then can't remember what?" }\end{array}$ \\
\hline $\begin{array}{l}\text { The Inventory of Everyday } \\
\text { Memory Experiences }\end{array}$ & Herrmann \& Neisser (1978) & $\begin{array}{l}\text { "How often do you discover, when you have just } \\
\text { gone out, that you must return for something } \\
\text { you had intended to bring but accidentally } \\
\text { left behind?" } \\
\text { "When you put some things away and then } \\
\text { look for it a week or so later, how often do you } \\
\text { forget where you had put it?" }\end{array}$ \\
\hline $\begin{array}{l}\text { The Cognitive } \\
\text { Failures Questionnaire }\end{array}$ & $\begin{array}{l}\text { Broadbent, Cooper, } \\
\text { FitzGerald \& Parkes (1982) }\end{array}$ & $\begin{array}{l}\text { "Do you find you forget why you went from one } \\
\text { part of the house to the other?" } \\
\text { "Do you find you forget appointments?" }\end{array}$ \\
\hline
\end{tabular}

Everyday Memory Questionnaire and the Subjective Memory Questionnaire, suggesting some degree of validity for these measures as tools for assessing prospective memory. However, Boake et al. (1995) only found this correlation to be present in a sub-sample (about half of the total sample) of their closed-head injured patients who they identified as valid responders on the Everyday Memory Questionnaire. Schwartz and McMillan (1989) found that while correlations between the RBMT and the Subjective Memory Questionnaire and Everyday Memory Questionnaire were statistically significant, they only accounted for a relatively small proportion of the total variance, suggesting that the two subjective and objective tests accounted for different aspects of impairment. In a study using the Memory Functioning Questionnaire, although scales which included prospective memory items correlated with tests of prospective memory in controls, these findings were not observed in the TBI group (Kinsella et al., 1996). More promising was a study by Ownsworth and McFarland (1999), who chose a subset of 24 items from the Cognitive Failures Questionnaire, Subjective Memory Questionnaire and the Inventory of Everyday Memory Experiences, based on high factor loadings and item reliabilities. They found that participants with acquired brain injury reported significantly greater memory problems than the controls on this questionnaire, and also scored significantly lower on the RBMT, typically failing those tests requiring prospective memory. In addition, the memory questionnaire was found to be significantly correlated $(-0.52$, $p<0.05)$ with the RBMT. Despite the better validity for this questionnaire, it is still a broad memory assessment tool and does not target prospective memory separately.

Greater validity for these questionnaires (specifically the Everyday Memory Questionnaire and Subjective Memory Questionnaire) has been found if completed by a relative or close friend of the TBI individual rather than by the individual themselves (Sunderland, Harris \& Gleave, 1984; Sunderland, Harris \& Baddeley, 1983; Schwartz \& McMillan, 1989). Studies also generally find that differences between groups may be more evident when comparing milder head injury and controls than when examining severe head injury (Sunderland et al., 1984; Mateer, Sohlberg \& Crinean, 1987), suggesting self-report questionnaires may be too demanding for severely brain 
injured people and so not an effective measurement tool (Boake et al., 1995).

Thus, although some evidence for validity of these everyday memory questionnaires as measures of prospective memory exists, it is rather weak when examined more closely. This is especially true when considering using self-report measures with severe TBI patients. These findings may be explained by the small number of items used to measure prospective memory within these questionnaires and their development as a more general memory assessment tool.

Hannon and colleagues (1990) developed one of the first specific questionnaires for assessing prospective memory, the Prospective Memory Questionnaire. The final version of the Prospective Memory Questionnaire comprised 52 items which formed four subscales: 1) long-term episodic (e.g., "I forgot to send a card for a birthday or anniversary", "I forgot to return books to the library by the due date"); 2) short-term habitual (e.g., "I forgot to lock the door when leaving my apartment or house", "I forgot to put a stamp on a letter before mailing it"); 3) techniques to assist memory (e.g., "I rehearse things in my mind so I will not forget to do them", "I make Post-It (sticky note) reminders and place them in obvious places"); and 4) internally cued (e.g., "I forgot what I wanted to say in the middle of a sentence", "I was driving and temporarily forgot where I was going"). To date, little research has used the Prospective Memory Questionnaire on populations with TBI. In one such study, 156 participants (114 normal students; 27 healthy retirement home residents; and $15 \mathrm{com}$ munity college students with TBI) were administered four tasks testing short-term prospective memory, two tasks testing long-term prospective memory, and the Prospective Memory Questionnaire (Hannon et al., 1995).

Reliability of the Prospective Memory Questionnaire was found to be high, with coefficient alpha ranging from $0.78-0.90$ for the subscales, and 0.92 for the total score, and test-retest reliability ranging from $0.64-0.88$. Mixed results were found for validity, with short-term prospective task performance significantly correlating with Prospective Memory Questionnaire total and subscale scores, but long-term tasks not significantly correlating in the expected direction. Further, comparisons between the three groups found the only significant difference occurring between the TBI and control students on the short-term habitual scale, suggesting low discriminating ability for the questionnaire between groups (Hannon et al., 1995).
Waugh (1999) developed another specific questionnaire of prospective memory. The Comprehensive Assessment of Prospective Memory measures three dimensions: (a) frequency of failure (39 items; e.g., "Forgetting to buy an item at the grocery store", "Leaving the iron on", "Forgetting to eat a meal", "Not locking the door when leaving home"), (b) amount of concern about these failures (using the same 39 items), and (c) reasons associated with the success or failure of prospective memory tasks (42 items; e.g., "I usually remember to do things for other people", "The more things [say two or three] I have to do, the more likely I will forget to do them", "I rely on other people to remind me when I have to remember to do things"). These dimensions are rated on five-point scales. The first two dimensions have two components common and uncommon prospective memory lapses. Common failures relate to instrumental activities of daily life (IADL), like household management activities of shopping, meal preparation etc. Uncommon failures relate to basic activities of daily living (BADL) — tasks such as dressing, eating and personal hygiene. In a normal population, reliability (Cronbach's alpha) for the common failures component was 0.92 and for the uncommon failures, 0.79. Validity was claimed by the ability of the two components to be sensitive in discriminating age groups (younger, middle, and older).

Roche, Fleming and Shum (2001) focused on the frequency count of the Comprehensive Assessment of Prospective Memory (i.e., the first dimension) in their comparison of $33 \mathrm{TBI}$ and 29 control participants. No significant differences were found between the two groups on the selfratings for either the BADL or IADL components. However, as shown with everyday memory questionnaires, significant differences were found between the two groups on the informant ratings for both components. The groups also differed significantly on self-awareness, with the TBI group underestimating and controls overestimating their frequency to forget when compared to their informants. Thus, validity for the Comprehensive Assessment of Prospective Memory was found to be low when used with people who had TBI, although no correlations between the Comprehensive Assessment of Prospective Memory scores and prospective memory tests were calculated to further explore the questionnaire's validity.

Based on the studies reviewed, the utility and validity of these self-report questionnaires are limited due to a number of issues. Firstly, people 
may just not know, or have enough insight, about their memory problems to accurately report their functioning (Sunderland et al., 1983; Cockburn, 1996). The amount of memory cues which a person uses in their everyday life can also distort their insight into their own deficits (Dobbs \& Rule, 1987). Those people who use a lot of memory aids, such as diaries and Post-It notes, may report their memory as very good because these aids are enhancing their remembering. However, their lack of memory lapses are not due to a good memory but to good compensatory devices. Additionally, people may forget their memory failures, which is especially true for people with TBI (Hickox \& Sunderland, 1992). Of course, unawareness of memory problems may also be psychogenic as well as neurogenic, with people using defensive denial to avoid being aware of those deficits which may lead to a negative emotional experience (Boake et al., 1995). Finally, low correlations between questionnaires and laboratory or psychological tests may reflect the fact that the two methods are indeed measuring different constructs (Cohen, 1989).

One likely reason for the lack of utility and low validity of these questionnaires is that most of them were not developed based on a theory of prospective memory. As a result, most of these questionnaires lack a thoroughness which objective tests provide (Cockburn, 1996) with only some of the processes involved in prospective remembering measured. However, this situation can be explained given that there is still much debate surrounding the nature and processes of prospective memory (Ellis \& Kvavilashvili, 2000). Theoretical refinement in this area is needed to advance the measurement of this construct.

Despite these issues with low validity and lack of theory, self-rating questionnaires are important tools in assessing and rehabilitating prospective memory for a number of reasons. Firstly, they provide insight into a person's everyday memory, which may not be accessed through psychological tests or laboratory studies that are theoretically rather than ecologically based (Mateer et al., 1987), and may not be evident in overt behaviour to a third-person observer (Sunderland et al., 1983). Secondly, they provide information about the beliefs that a person has about their own abilities, which can then influence their behaviour (Cockburn, 1996; Hannon et al., 1995). They are also cheap and simple, which allows administration to a large number of people in a relatively short time (Sunderland et al., 1983).

Therefore, as an assessment tool, questionnaires need to be based on theory and be specific to prospective memory. In addition, unless validity is increased in self-reports, their use should be restricted as a tool for understanding a person's beliefs about their memory rather than as a true measure of their ability, especially in the case of patients with severe TBI. Questionnaires which measure reports of both self and others would allow the assessment of a person's subjective beliefs as well as a more objective and valid assessment of that person's ability from an outside source.

\section{Psychological Tests}

Few psychological tests have been developed to directly measure prospective memory. In fact, the Rivermead Behavioural Memory Test (RBMT) is the only such test that is widely used in clinical practice (Titov \& Knight, 2000), although prospective memory is only one construct, along with retrospective memory, measured in this test. Three prospective memory tasks are included in the RBMT: (a) remembering where a belonging is hidden and asking for it to be returned; (b) asking for the next appointment time when an alarm sounds; and (c) delivering a message.

Results supporting the validity of the RBMT in patients with brain injury have been mixed. Mills and colleagues (1997) found low validity for prospective memory ability in their comparison of the RBMT with remembering to do daily tasks, in 6 neurologically impaired outpatients of a post-acute community rehabilitation program. Their tasks were to be completed in the morning on each of 5 days, with no verbal or visual cues given. A verbal cue, after their lunch break, was given by staff reminding them that their daily responsibilities needed to be completed before the beginning of afternoon activities. Correlations between responsibilities completed and the prospective memory tasks on the RBMT were low and non-significant with a high correlation found between responsibilities completed and the retrospective RBMT tasks $(r=0.83, p<0.05)$.

Conversely, Makatura and colleagues (1999) compared the total RBMT's accuracy in distinguishing degree of everyday memory functioning with traditional clinical memory measures (Wechsler Memory Scale-Revised (WMS-R) and the Luria Nebraska Neuropsychological Battery (LNNB-M)) among patients with head injuries. The Clinicians Memory Rating Scale (CMRS) was developed for this study to measure subjects' everyday memory functioning (including prospective memory) by a clinician who had face-to-face 
contact with the subjects for a number of weeks. Based on the CMRS scores, four groups were distinguished: severe $(n=20)$, moderate $(n=29)$, mild $(n=39)$, and no $(n=31)$ memory impairment. The RBMT was found to be more accurate in identifying subjects' everyday memory functioning than either of the traditional memory tests and the correlations between these two tests was greater than with the RBMT, suggesting greater validity for the RBMT as an assessment tool for everyday memory.

The validity of the RBMT as a predictor of long-term memory impairment has also been investigated recently (Wiseman et al., 2000). Seventytwo people with TBI and total baseline RBMT scores were administered three prospective memory tasks and had their memory rated by themselves and an informant, 10 years later (on average). Results of the study suggested that baseline measures of RBMT were predictive of objective memory measures and informant reports of impairment many years following TBI.

The inability of the RBMT to detect more subtle memory deficits in patients, prompted De Wall and colleagues (1994) to produce the Extended Rivermead Behavioural Memory Test (RBMT-E). By combining two parallel forms of the RBMT, they developed a more demanding test that would eliminate ceiling effects and thus, be more sensitive to minor memory problems. Wills, Clare, Shiel \& Wilson (2000) administered the RBMT-E on a group of brain injured people who had 6 months previously scored on the normal range of the RBMT, despite their experiencing everyday memory problems, and a control group. The brain-injured group was also retested on the RBMT. For all patients, classifications on the RBMT were either similar or worse on the RBMT-E, supporting its ability to better discriminate among less severe patients. Total profile scores on the RBMT-E were significantly different between the two groups. However, despite having scored in the normal range 6 months prior, only 7 of the 16 subjects were similarly classified on the retest of the RBMT, with the remaining 9 subjects scoring in the "poor" and "moderately impaired" range. Thus, when comparing only those participants who scored in the normal range on the retest with the controls, no significant differences were found. Also, the tasks designed to test prospective memory did not show significant differences between the groups. Therefore, the RBMT-E has not yet been shown to be more sensitive in detecting prospective memory problems in those patients with minor TBI.
A new test has recently been developed, which solely measures prospective memory. The Cambridge Behavioural Prospective Memory Test comprises four time-based and four eventbased prospective memory tasks and takes about 40 minutes to administer (Wilson \& Evans, unpublished). While a time-based task involves remembering to perform an action at a specific time, an event-based task involves remembering to perform an action when an external cue appears. The person is required to remember to do the tasks while performing filler tasks (e.g., nonverbal reasoning tests). The four time-based tasks are: (a) reminding the tester after 15 mins not to forget their key, (b) requesting the tester for a newspaper after 20 mins, (c) after working for 20 mins on the first filler task, switching to a second filler task after a further 5 mins, and (d) opening or closing the booklet of the filler task 3 mins after the instruction is given. The four eventbased tasks are: (a) reminding the tester about five hidden objects after the tester says the testing is over, (b) putting a briefcase under the desk after an alarm rings which is set to ring 5 mins after the beginning of the session, (c) changing pens after having completed seven filler assignments, and (d) giving an envelope with "message" written on it to the tester when the tester says that there are 10 mins left. Additionally, the person is told they can use any strategy to help them remember the tasks (with pen and paper clearly visible for them to use - though not verbally mentioned).

In a study with 36 brain-injured participants and 28 controls, the brain-injured group were found to perform significantly worse on the Cambridge Behavioural Prospective Memory Test tasks than the controls (Groot, Wilson, Evans \& Watson, in press). The Cognitive Failures Questionnaire and Everyday Memory Questionnaire were also given to both brain-injured participants and their carers and to controls only. The only association found between scores on the Cambridge Behavioural Prospective Memory Test and the questionnaires was the Everyday Memory Questionnaire carers' ratings. According to the authors, norms are being collected for this test and the final version of the test will be published in 2002 (Wilson, personal communication). However, more research is still needed to establish the validity and reliability of the Cambridge Behavioural Prospective Memory Test to determine its usefulness as an assessment tool for prospective memory.

Another test developed specifically to assess prospective memory is the Memory for Intentions Screening Test (Raskin \& Buckheit, 2000). This test takes about half an hour to administer and has 
two alternate forms. For each form there are eight prospective memory tasks. Half the tasks require verbal responses, for example, "Tell me that it is time to take a break" and half require an action, for example, "Sign your name on your paper". Further, four tasks are time-based (e.g., "In fifteen minutes...") and four are event/cue-based (e.g., "When I hand you a red pen..."), although these are not evenly distributed between the verbal and action tasks (i.e., three of the verbal responses are time-based tasks and one of the action responses is time-based). As yet, the Memory for Intentions Screening Test is unpublished and its psychometric properties are unknown but some norms have been collected for younger, middle-aged, and older adults (Raskin, personal communication).

The advantages of using psychological tests are their objectivity in measuring a given construct. Also, the collection of norms for a variety of populations including different age groups, gender and clinical groups, allow for comparisons within and between groups. Thus, how problematic a person's prospective memory may be, can be determined through quantifying their abilities and comparing them to people of similar circumstances. One of the problems with some of the tests reviewed is the small number of items chosen to assess prospective memory, due to tests not being designed specifically to assess prospective memory. For example, in the RBMT, there are only three items used. This has the effect of making the scores unreliable.

The development of psychological tests of prospective memory is again hampered by the lack of agreement amongst researchers on the underlying theory which is important for creating test items. Although, both the Cambridge Behavioural Prospective Memory Test and the Memory for Intentions Screening Test have operationalised the prospective memory construct based on findings that support the differentiation between time- and event-based tasks. Despite the development of these new tests, there is still a great need for development of new tests of prospective memory that are theory driven, with proven psychometric properties and extensive norms.

\section{Experimental Procedures}

Experimental procedures for studying human memory are usually developed based on a theory or model of cognition, and they are usually more analytical and well controlled. However, many procedures which are undertaken in a laboratory setting are criticised for their contrived nature and lack of ecological validity. In addition, unlike psychological tests, most of these procedures are not designed for clinical usage and so norms and psychometric properties are not deemed necessary. Few experimental procedures have been developed for the measurement of prospective memory and even fewer have been used on populations with TBI.

In a study by Cockburn (1996), 18 inpatients with recently acquired brain damage were compared with 18 controls. Two prospective memory tasks were given to each group. The time-based task was incorporated in a sentence-verification filler activity with participants asked to start a timer when ready to begin the task and then stop the timer and activity after 5 minutes. The eventbased task was incorporated into an activity which required crossing out the lowest number in each row of numbers in a booklet. Participants had to change from using a black to a red pen when the numbers changed from 2 to 3 digits and to sign their initials at the end of the last page. The brain injured group were also administered formal tests to measure executive function, and the RBMT and prose recall from the WMS to measure retrospective memory.

Significantly more controls than patients were accurate on the two prospective memory tasks. Within the patient group, the measures of retrospective memory revealed significant differences between the success rate on the eventbased task. The authors suggested that this indicates that retrospective memory plays a part in performance of an event-based prospective memory task, although it would have been interesting to see if these same differences existed within the control group who were not administered the formal memory tests. Other limitations of the study include the use of a heterogeneous group of patients (e.g., TBI, CVA, subarachnoid haemorrhage, and tumour) and a small number of responses.

Shum et al. (1999) examined more extensively the effect of TBI on prospective memory. Their main aim was to more fully operationalise prospective memory into time-, event- and activity-based tasks and to use more responses rather than only a couple as most studies have done, in order to increase the reliability of their assessment of prospective memory.

Two computer programs, consisting of general knowledge questions, were developed to administer the time-based task and the event-based task, to a group of 12 TBI patients and a matched control group. On the time-based task, participants were asked to telephone the experimenter every 5 
minutes to report their cumulative percentage correct on the general-knowledge task. To keep track of the time, participants were told that they could press the " $t$ " key on the keyboard to display a digital clock. For the event-based task, participants were asked to telephone and report their cumulative percentage correct whenever "Prime Minister" appeared in a question. Participants were asked to telephone at the start of each 5-min interval or as soon as they saw the target words, but that if they forgot, to telephone as soon as they could remember. For the activity-based task, they were told to do three things once they finished the experiment: 1) write down their cumulative percentage correct on the whiteboard; 2) switch off the computer monitor; and 3) switch off the "testing in progress" light outside the laboratory.

The TBI group performed significantly more poorly than the controls on the time-, event- and activity-based tasks. When asked at the end of the study, all participants were able to remember the instructions and requirements for the prospective memory tasks, ensuring that incorrect responses were due to difficulties in remembering to perform the action rather than the content of the task. However, the relationship between performances on the three prospective memory tasks and everyday functioning had not been demonstrated.

Recent studies by Titov and Knight (2000; 2001) endeavoured to assess prospective memory in a procedure much more true to life, but in a controlled environment. They developed a videobased procedure in which the person views a shopping centre and must remember to perform certain actions when cued by areas of the store. In studies with a normal population, they found high concurrent validity $(0.71)$ for the video task with an in vivo experiment in which the same procedure was conducted with the subjects walking through the shopping centre. Further, reliability was higher for the video procedure when the shopping district was known to the participant, again supporting the validity of this procedure (Titov \& Knight, 2001).

This video procedure was then tested on 12 clients undergoing rehabilitation for neurological impairments at a community-based clinic (Titov \& Knight, 2000). Participants were divided into two groups, no or mild memory problems $(n=5)$ and moderate-to-severe problems $(n=7)$.

All clients participated in both the video and in vivo procedures. Ten items comprising of a unique cue and an associated action were assessed, with three of the items involving purchases (e.g., "Buy a CD"), three involving carrying out some other action in the shop (e.g., "Ask about the sizes of towels"), and four involving answering a question in response to a cue (e.g., "Does the shop sell bicycles?"). In both procedures the participants were asked to report all the cues that were relevant and to recall the associated action when it arose. At the end, the participants were presented with each of the 10 cues (e.g., "Towels") and asked to recall the associated task (e.g., "Ask about the sizes") — this constituted the "cued recall" score. Three WMS-III subtests were also administered to the subjects. After completing both experimental procedures, participants were asked to rate how well they thought their performance reflected their usual abilities.

A significant effect for tasks recalled, cues recognised and cued recall was found for group. There were no significant differences between mean scores on the video and real life tasks and no significant group by method interaction. Intraclass correlations between procedures demonstrated high validity for tasks recalled $(r=0.80, p<0.01)$ and cues recognised $(r=0.79$, $p<0.01)$ but not for the cued recall test $(r=0.20$, $p>0.05)$. Internal consistency reliability of the tasks recalled scores for the two measures showed estimates of 0.75 for the in vivo and 0.63 for the video procedures.

Although the experimental procedures are more realistic than psychological tests, and allow more direct assessment of prospective memory than questionnaires, they still have many limitations. Firstly, the tasks are set by the experimenter. Generally, people choose and plan their own future intentions which makes them more meaningful and thus more easy to remember. For example, asking a person to remember to buy a set of specified groceries at the grocery store cannot be compared to a person who goes to buy grocery items for themselves independently. In the first case, the experimenter may tell the participant a list of items that they would never buy themselves or not even know what a particular product was. However, in the second case, the person has possibly planned what meals they want to make, what ingredients are needed, what things they have run out of and goes accordingly to buy those products. Thus, forgetfulness in the former instance is more understandable than in the latter scenario. Further, ingredients for a specific meal can be grouped together as one piece of information in the person's mind, instead of having to remember each piece of food individually, thus making the information more meaningful. Therefore, simply by making a scenario for a 
prospective memory task more realistic does not necessarily make it more valid.

Also, unlike in the video task of Titov \& Knight $(2000 ; 2001)$, in real life, people are able to retrace steps if they forget something the first time they pass it by. An important component of prospective memory can be the planning of strategies needed for carrying out the intentions and also searching in a non-linear way when a reminder is missed (Titov \& Knight, 2000).

However, despite these issues, the strong validity and reliability of experimental procedures far exceeds those of questionnaires and psychological tests, used to measure the same construct. They are also more controlled and theoretically driven than the previous assessment methods. It would be useful for future research to develop procedures that allow more flexibility for the participant to participate in the planning and even the selection of the tasks for which they must remember.

\section{Treatment of Prospective Memory Impairment}

It has been suggested that research into the nature of prospective memory function may facilitate the development of rehabilitation programs (Cockburn, 1996; Kinsella et al., 1996), but little has been written about techniques specifically for the rehabilitation of prospective memory with people with TBI (Klonoff, O'Brien, Prigatano, Chiapello \& Cunningham, 1989). (For an exception, see the chapter by Cockburn, 1996). In addition, there have been few studies investigating the effectiveness of rehabilitation techniques for prospective memory.

The rehabilitation of cognitive deficits, including memory, is generally categorised into two main approaches: remedial or restorative approaches and adaptive or compensatory approaches (Hutchinson \& Marquardt, 1997; Sohlberg \& Mateer, 1989a; Unsworth, 1999; Van den Broek, Downes, Johnson, Dayus \& Hilton, 2000). Remedial approaches emphasise restoring the underlying defective cognitive functions usually via repetitive drills or training activities designed to stimulate damaged neural networks or establish new networks. Adaptive approaches concentrate on the use of compensatory strategies, environmental modifications, and intact cognitive functions to maximise functional performance. Both approaches are applicable to the rehabilitation of prospective memory dysfunction, and in clinical practice may be used in a complementary fashion. This section reviews the repertoire of such techniques available to the clinician, including reme- dial training programs, and internal and external compensatory strategies.

\section{Remedial Approaches}

Whilst it is generally accepted that rehearsal, drills or repetitive practice methods are of little value in the restoration of memory in people with brain injury (Hutchinson \& Marquardt, 1997; Kim, Burke, Dowds, Robinson Boone \& Park, 2000; Raymond, Malia, Bewick \& Bennett, 1996; Sohlberg \& Mateer, 1989a; Van den Broek et al., 2000), this conclusion is primarily based on retrospective memory research. Criticism of this approach has been centred on the task-specific nature of any improvements and failure to generalise gains to functional activities outside the clinic setting (Sohlberg \& Mateer, 1989a). Despite this, the use of "memory training" or stimulation activities is not uncommon in the clinical setting, and generally targets retrospective recall, such as computer programs which require recall of words, stories, digits or pictures.

With regards to improving prospective memory, there is some mounting evidence that a remedial or training approach may have some merit in TBI rehabilitation. Sohlberg and colleagues (Sohlberg, White, Evans \& Mateer, 1992a, 1992b; Raskin \& Sohlberg, 1996) described a number of case studies using a prospective memory training technique involving repetitive administration of prospective memory tasks. The prospective memory training approach involved systematically increasing the interval between the request to initiate a specific task (a two step motor command) and time of task execution. Missed trials were followed by a series of prompts. Although impressive gains were reported, for example increasing prospective memory ability to 5 and 10 minutes in amnesic subjects (Raskin \& Sohlberg, 1996), the prospective memory training method was a time consuming and labour intensive process with sessions lasting between 4 and 6 hours per week over several months (Sohlberg et al., 1992a). There was ambiguous evidence that the gains in prospective memory ability were generalised to naturalistic, real-life prospective memory tasks (Raskin \& Sohlberg, 1996), and it was not stated if gains were sustained after the cessation of treatment.

Similar "spaced retrieval" training programs have been used to improve prospective memory in people with Alzheimer's Disease (Camp, Foss, Stevens \& O'Hanlon, 1996; McKitrick, Camp $\&$ Black, 1992). By practising the retrieval of specific information over increasing intervals, 70\% 
of participants $(n=30)$ in one program displayed the ability to perform an assigned action after a 1week interval (Camp et al., 1996). The ecological value of this method was then demonstrated by successfully training $87 \%$ of participants $(n=23)$ to learn the strategy "look at the calendar" to remind them of scheduled daily activities.

Given Sohlberg and colleagues' initial encouraging results with prospective memory training in brain injury case studies, this type of technique may also be useful for training individuals with TBI to use external memory aids such as diaries or calenders more effectively. It may also have application for learning routine activities of daily living such as remembering to take medication or to phone a care-giver, or various vocational tasks such as remembering to put on an identification badge or sign a timesheet.

Some theoretical explanations have been put forward for the gains seen in prospective memory using a repetitive training approach. These involve the intensive activation of control processes or the facilitation of a deeper level of processing (Sohlberg et al., 1992a), the teaching of specific skills such as vigilance to time and task (Raskin \& Sohlberg, 1996), and the use of procedural or implicit memory to enhance learning at an unconscious level (Camp et al., 1996; Cockburn, 1996). Further research into prospective memory training is indicated to establish the effectiveness of this approach, and the sustainability and generalisation of gains in prospective memory ability.

Furthermore, using a training approach to improve other cognitive functions underlying memory has also been advocated. It is thought that memory can be indirectly rehabilitated by training aimed at improving attention, pacing, information processing, and organisation (Hutchinson \& Marquardt, 1997; Raymond et al., 1996). In addition to these cognitive functions, prospective memory requires the frontal lobe mechanisms responsible for planning, decision making, and inhibitory control to be intact (Cockburn, 1995). Therefore, there may be some flow on effect from computer activities and penand-paper tasks focussing on remediating attentional and executive dysfunction. The value of such an approach for prospective memory remediation remains to be investigated.

\section{Compensatory Approaches}

In contrast to remedial approaches which are aimed at restoring the defective memory function, many clinicians prefer to adopt compensatory approaches which are aimed at maximising residual abilities and drawing on strategies to assist remembering (Raymond et al., 1996). Such strategies can be broadly classified into internal and external strategies or aids to memory (KotlerCope \& Camp, 1990).

\section{Internal Strategies}

Internal strategies or mnemonics involve the mental organisation and encoding of information in a way that assists recall (Sohlberg et al., 1992a). Effective prospective memory involves not only the encoding, storage and activation of the intention to perform an action in a designated context, it also involves retrospective retrieval of the content of that intention (Cockburn, 1996). Internal memory strategies probably have more application to the rehabilitation of prospective memory by enhancing recall of the content (the retrospective component) than in enhancing recall of the intention.

Internal strategies can be further divided into organisational and encoding methods (Belleza, 1981). The most well known organisational methods include "peg-words" and "method of loci" relying on paired associate learning (Sohlberg et al., 1992a). Visual imagery is the most commonly used encoding method, in which abstract words or numbers are encoded as meaningful visual images. These visual images may then be linked in some way, for example using a story, so combining encoding and organisational methods in the one strategy. Other internal strategies involve the use of operant/self-instructional techniques (e.g., the PQRST study method for recalling written material) and verbal techniques (e.g., first letter cuing). For a full description of internal mnemonic devices see Belleza (1981).

Belleza (1981) emphasised that self-generated mnemonic devices are more effective in aiding recall than mnemonics that have been imposed on the individual. Yet this is true only if the learner is capable of generating the strategy. It is doubtful whether individuals with compromised cognitive ability due to brain injury are able to adequately generate and apply internal strategies in real-life situations (Raymond et al., 1996, Sohlberg et al., 1992a). This may be due to limitations in the generation of visual images or creative verbal strategies or the fact that many techniques do not lend themselves to application in everyday activities (Sohlberg \& Mateer, 1989a). Thus, the generalisation of internal strategies beyond the training period and outside the clinical setting is suspect. Nevertheless, there has been a lack of research investigating the efficacy 
of internal memory strategies with people with TBI, particularly in relation to prospective memory.

In a sample of community dwelling, nondemented older people $(n=20)$ (Andrewes, Kinsella \& Murphy, 1996), training in the use of a memory handbook on internal strategies was not effective in improving prospective memory test performance. However, the memory handbook group did show significantly better everyday memory, measured by diary studies, compared to a placebo control group $(n=20)$. They also showed better knowledge of strategies as measured by questionnaire, leading the authors to conclude that specific training in the use of internal strategies such as peg-words is particularly important for the older population. This suggests that training sessions and handbooks may also assist people with brain injury to use internal strategies, but perhaps this may be more effective in people with mild to moderate injuries, and hence less severe cognitive impairment.

Furthermore, Thompson (1996) advocated the use of relaxation training to enable patients with brain injuries to practice the generation of visual images for use in memory strategies. However, little empirical evidence exists to either support or oppose the use of internal strategies in prospective memory rehabilitation after brain injury.

\section{External Strategies}

In contrast to internal strategies, external memory aids involve reliance on environmental modifications or some external device to either organise information or to provide a cue or reminder (Sohlberg \& Mateer, 1989a). Environmental modifications may involve notices, Post-It notes, labelled shelves, and structured work environments designed to compensate for memory deficits. Organisational devices may include electronic diaries, memory notebooks, and computers. Cues for prospective memory involve the use of alarms, buzzers, calendars, watches and electronic devices such as NeuroPage (Hersh \& Treadgold, 1994) to remind one to perform a task at a particular time. Thompson (1996) summarised a number of external strategies for use with people with brain injury, many of which are applicable to compensation for prospective memory deficits. These included, for example, keeping a daily calendar, using a noticeboard to display information, making a list of tasks to be done, leaving items that are needed in a prominent place, adherence to routines, setting out tasks in order of priority, and writing tasks on the back of one's hand. A recent study (Groot et al., in press) found that participants who spontaneously took notes ( 13 out of 36 people with brain injury and 14 out of 28 controls) performed significantly better on a prospective memory test than those who did not take notes, $t(62)=-3.26, p<.01$, leading to the conclusion that note-taking significantly benefits prospective memory functioning.

Kotler-Cope and Camp (1990) noted that external memory aids require less effort than internal strategies, and are more commonly used by the elderly. They are also more relevant to everyday functioning, and thus more easily generalised to outside of the clinical setting but, because they involve reliance on a visible means of support, may be met with poor acceptance by patients. These issues of generalisation and patient acceptance are equally applicable to persons with brain injury. Cognitive impairment may limit the generalisation of techniques learnt in therapy (Raymond et al., 1996). Diminished selfawareness, and hence compliance with compensatory strategies, is also not uncommon in this population (Fleming, Strong \& Ashton, 1998).

In enhancing prospective memory function, external memory aids are thought to be useful for both the trigger of the intention (the prospective component) and the retrieval of the content (the retrospective component) (Vortac, Edwards \& Manning, 1995). Research has shown that eventbased prospective memory tasks which are cuedriven are easier to remember than time-based tasks which are self-initiated (Sellen, Louie, Harris \& Wilkins, 1997). In fact, Otani et al. (1997) suggested that, for an event-based task, the prospective component is recalled automatically in response to the trigger. Therefore, conversion of a time-based prospective memory task into an event-based task, by the use of an alarm, or linking the task to an event (e.g., taking medication at mealtimes) has been recommended (Shum et al., 1999). Thus, research supports the use of an external strategy or aid to provide a trigger for prospective memory tasks, however this requires further investigation with the brain injury population.

Wilson (1995) noted that external cues are of little use for people with brain injury who may be unable to access internally stored information in response to a cue. In this case, the retrospective component of the prospective memory task can be assisted by the use of an organisational device. Diaries or memory notebooks are perhaps the most commonly recommended external device for use with people with brain injury (Hutchinson \& Marquardt, 1997; Ownsworth \& McFarland, 1999). However, many patients quickly abandon diary use once discharged (Lynch, 1995), 
suggesting problems with poor generalisation and patient acceptance. To overcome such problems, several formal training approaches to memory notebook use have been devised for use in TBI rehabilitation (Burke, Danick, Bemis \& Durgin, 1994; Ownsworth \& McFarland, 1999; SchmitterEdgecombe, Fahy, Whelan \& Long, 1995; Sohlberg \& Mateer, 1989b; Zencius, Wesolowski, Krankowski \& Burke, 1991).

Sohlberg and Mateer (1989b) described a formal training approach to memory notebook use. The approach, based on learning theory, has three phases (acquisition, application and adaptation). However, the duration of the intense training (6 months) described by the authors in a case study illustration may be prohibitive in many clinical settings (Cockburn, 1996). Zencius et al. (1991) described four case studies in which the use of memory notebooks improved performance for correctly completing homework assignments and keeping appointments.

Burke et al. (1994) detailed another process approach to memory notebook training which focussed on raising self-awareness of memory deficits in order to minimise patient resistance. They also describe a case study of a patient with traumatic brain injury who successfully adopted memory notebook use following training. Both approaches (Burke et al., 1994; Sohlberg \& Mateer, 1989b) emphasised the importance of training for generalisation of the strategy. This was achieved by involving family and friends in the training and practice in community-based settings. For further information on facilitating the generalisation of memory treatments, see Sohlberg and Raskin (1996).

Schmitter-Edgecombe et al. (1995) compared a memory notebook training program to supportive group therapy with eight closed head injury participants randomly assigned to the two treatment groups. The notebook training program consisted of 16, 60-minute sessions over a 8 weeks and was composed of four stages: anticipation, acquisition, application and adaptation. Participants in the notebook training reported significantly less everyday memory failures posttreatment than the supportive therapy participants, $F(1,5)=7.15, p<.05$, but the difference was no longer significant at a 6-month follow-up. The authors noted that group settings provided a positive forum for teaching participants to use the memory notebook. Participants appeared to benefit from interactions with, and encouragement provided, by other people who were in similar situations. Ownsworth, McFarland and Young (2000) in a study of a self-regulation skills training program found similar benefits of group support for adults with acquired brain injury. These included increased social interaction, communication skills and altered social behaviour. Although there appears to be positive outcomes in using group format for training, SchmitterEdgecombe et al. (1995) suggested that further research is required, and concluded that perhaps the full potential of each participant is not always achieved with this approach.

Evidence to support these memory training approaches has been based only on descriptive case studies or very small sample sizes. An exception is the controlled study by Ownsworth and McFarland (1999). With a total sample size of 20 participants, they found that a Diary and SelfInstructional Training (DSIT) approach was significantly better than a Diary Only approach in terms of number of diary entries, reported memory problems and participant-ratings of treatment efficacy. Furthermore, the above approaches were designed to compensate for memory impairment in general and did not specifically target prospective memory. To do so, it would be necessary to incorporate both cues for the intention and an organisational device for recall of the content of the prospective memory task.

In our electronic age it is not surprising that devices that were originally created for the business world, are now being assessed for their feasibility in helping people who have cognitive impairments. The Voice Organiser is a hand held electronic device that recognises the user's voice patterns. It was recently trialed as an electronic memory aid in a training program involving five survivors with acquired brain injury who had significant prospective memory impairment (Van den Broek et al., 2000). Each subject was trained to record messages and to set the voice activated alarm, so that the Voice Organiser would prompt the subject throughout each day. The results of this study indicated that with this small sample size, prospective memory can be substantially improved by using external compensatory devices such as the Voice Organiser.

Microcomputers are another recent addition to the clinical repertoire used to facilitate everyday prospective memory function. Palmtop computers have the facility to provide visual as well as auditory cues such as an alarm feature. These computers are advantageous in that they are small, lightweight yet able to store detailed information. Kim et al. (2000) trialed a palmtop computer with 12 patients who had prospective memory deficits. Nine out of 12 subjects reported the external memory aid to be useful and effective on a daily 
basis. Some of the benefits described included increased personal confidence, elevated self esteem, and a higher level of independence in activities of daily living. Although research to date has implied the success of these palmtop computers, more empirical evidence is required to establish cost feasibility with this population (Kim, Burke, Dowds \& George, 1999).

Although most people use external memory aids at some time, some people with brain injury may be reluctant to rely on them in the belief that their memory will not get better unless they use it. Wilson (1995) argued that this is unlikely to occur, and that patients should be encouraged to use any strategies that work for them. Furthermore, a study comparing community dwelling students with brain injury to non-injured controls showed that students with brain injury were not using compensatory techniques any more than controls although their actual prospective memory performance was poorer (Hannon et al., 1995). Such findings suggest that current rehabilitation approaches may be unsuccessful in equipping patients with useful strategies to use in the community. Reasons of poor self-awareness, and poor acceptance and generalisation of strategies may be contributing factors. This emphasises the importance of working with patients to improve selfawareness of deficits, select the most appropriate strategies, and tailor these specifically to their individual needs, rather than providing patients with a wide range of possible strategies, and leaving it to them to select and apply them. Clearly, more research using control groups is required to determine the usefulness of external strategies in enhancing prospective memory in patients with TBI, and to determine the extent and type of training programs required for successful generalisation of the strategies.

\section{Conclusion}

In this paper we aimed to review the current literature on the assessment and treatment of prospective memory dysfunction in adults with TBI. Prospective memory is a relatively new concept, which appears to have important consequences for successful independent functioning in the community. As noted by Winograd (1988) a person with a poor retrospective memory is seen as having an unreliable memory, but a person with a poor prospective memory is seen as an unreliable person.

We have described a number of approaches available to the clinician for assessing prospective memory function including questionnaires, psychological tests and experimental procedures. Amongst these three procedures, questionnaires and psychological tests are more suitable for clinical practice. However, compared to experimental procedures, they are not as well-defined and analytical, although, experimental procedures have been criticised for lacking in ecological validity. Overall, all three procedures are limited by the lag of theoretical development in the area of prospective memory. As a result, items and procedures used were not derived or developed based on a comprehensive theory. Once this problem is overcome, then the utility of these procedures need to be demonstrated through evaluation of psychometric properties and collection of representative norms.

In terms of rehabilitative technique for memory impairment, although much has been written about interventions for retrospective memory, there is relatively little evidence to guide practice for prospective memory. Some intervention methods which show promise include a prospective memory training approach, diary or memory notebook use, and electronic aids to memory. Further controlled trials with larger sample sizes is required to investigate these methods more thoroughly. In addition we noted two problems commonly experienced following TBI, namely impaired self-awareness and failure to generalise, which may pose obstacles in prospective memory rehabilitation. The importance of working closely with individuals to tailor therapy to their needs and to practise techniques learnt in multiple real-life contexts is seen as essential to the success of any prospective memory rehabilitation approach.

\section{References}

Andrewes, D.G., Kinsella, G., \& Murphy, M. (1996). Using a memory handbook to improve everyday memory in community-dwelling older adults with memory complaints. Experimental Aging Research, 22, 305-322.

Belleza, F.S. (1981). Mnemonic devices: Classification, characteristics and criteria. Review of Educational Research, 51, 247-275.

Bennett-Levy, J., \& Powell, G.E. (1980). The Subjective Memory Questionnaire: An investigation into the self-reporting of 'real life' memory skills. British Journal of Social and Clinical Psychology, 19, 177-188.

Boake, C., Freeland, J.C., Ringholz, G.M., Nance, M.L., \& Edwards, K.E. (1995). Awareness of memory loss after severe closed-head injury. Brain Injury, 9, 273-283. 
Broadbent, D.E., Cooper, P.F., FitzGerald, P., \& Parkes, K.R. (1982). The Cognitive Failures Questionnaire and its correlates. British Journal of Clinical Psychology, 21, 1-16.

Burke, J.M., Danick, J.A., Bemis, B., \& Durgin, C.J. (1994). A process approach to memory book training for neurological patients. Brain Injury, 8, 71-81.

Butters, M.A., Soety, E.M., \& Glisky, E.L. (1996) Memory rehabilitation. In P.J. Snyder \& P.D. Nussbaum (Eds.), Clinical neuropsychology. Washington DC: American Psychological Association.

Camp, C.J., Foss, J.W., Stevens, A.B., \& O’Hanlon, A.M. (1996). Improving prospective memory task performance in persons with Alzheimer's disease. In M. Brandimonte, G.O. Einstein \& M. McDaniel (Eds.), Prospective memory: Theory \& applications. Hillsdale, NJ: Erlbaum.

Cockburn, J. (1995). Task interruption in prospective memory: A frontal lobe function? Cortex, 31, 87-97.

Cockburn, J. (1996). Failure of prospective memory after acquired brain damage: preliminary investigation and suggestions for future directions. Journal of Clinical and Experimental Neuropsychology, 18, 304-309.

Cohen, G. (1989). Memory in the real world. Hillsdale: Erlbaum.

Dalla Barba, G. (1993). Prospective memory: A 'new' memory system? In F. Boller \& J. Grafman (Eds.), Handbook of Neuropsychology (vol. 8). Amsterdam: Elsevier.

de Wall, C., Wilson, B.A., \& Baddeley, A.D. (1994). The Extended Rivermead Behavioural Memory Test: A measure of everyday memory performance in normal adults. Memory, 2, 149-166.

Dobbs, A.R., \& Rule, B.G. (1987). Prospective memory and self-reports of memory abilities in older adults. Canadian Journal of Psychology, 41, 209-222.

Einstein, G.O., \& McDaniel, M.A. (1990). Normal aging and prospective memory. Journal of Experimental Psychology: Learning, Memory, and Cognition, 16, 717-726.

Einstein, G.O., McDaniel, M.A., Manzi, M., Cochran, B., \& Baker, M. (2000). Prospective memory and aging: Forgetting intentions over short delays. Psychology and Aging, 15, 671-683.

Einstein, G.O., McDaniel, M.A., Richardson, S.L., Guynn, M.J., \& Cunfer, A.R. (1995). Aging and prospective memory: Examining the influences of self-initiated retrieval processes. Journal of Experimental Psychology: Learning, Memory, and Cognition, 21, 996-1007.

Ellis, J. (1996). Prospective memory or the realisation of delayed intentions: A conceptual framework for research. In M. Brandimonte, G.O. Einstein, \& M.A. McDaniel (Eds.), Prospective memory: Theory and applications. Mahwah, NJ: Erlbaum.

Ellis, J., \& Kvavilashvili, L. (2000). Prospective memory in 2000: Past, present, and future directions. Applied Cognitive Psychology, 14, S1-S9.
Fleming, J., Strong, J., \& Ashton, R. (1998). Cluster analysis of self-awareness levels in adults with TBI. Journal of Head Trauma Rehabilitation, 13, 39-51.

Geffen, G.M., Butterworth, P., Forrester, G.M., \& Geffen, L.B. (1994). Auditory verbal learning test components as measures of the severity of closedhead injury. Brain Injury, 8, 405-411.

Gilewski, M.J., \& Zelinski, E.M. (1988). Memory Functioning Questionnaire. Psychopharmacology Bulletin, 24, 665-670.

Goldstein, F.C., \& Levin, H.S. (1995). Post-traumatic and anterograde amnesia following closed head injury. In A.D. Baddeley, B.A. Wilson \& F.N. Watts (Eds.), Handbook of memory disorders. Chichester: John Wiley \& Sons.

Groot, Y.C.T., Wilson, B.A., Evans, J., \& Watson, P. (in press). Prospective memory functioning in people with and without brain injury. Journal of the International Neuropsychological Society.

Hannon, R., Gipson, M.T., Rebmann, M., Keneipp, J., Sattler, J., Lonero, P., Day, C.L., \& Bolter, J.F. (1990, November). Self-rating of prospective memory by normal, brain-injured and alcoholic individuals. Paper presented at the meeting of the National Academy of Neuropsychology, Reno, NV.

Hannon, R., Adams, P., Harrington, S., Fries-Dias, C., \& Gipson, M.T. (1995). Effects of brain injury and age on prospective memory self-rating and performance. Rehabilitation Psychology, 40, 289-298.

Haut, M.W., Petros, T.V., Frank, R.G., \& Lamberty, G. (1990). Short-term memory processes following closed head injury. Archives of Clinical Neuropsychology, 5, 299-309.

Hermann, D.J., \& Neisser, U. (1978). An inventory of everyday memory experiences. In M.M. Gruneberg, P.E. Morris, \& R.N. Sykes (Eds.), Practical aspects of memory. London: Academic Press.

Herrmann, D.J. (1983). Questionnaires about memory. In J.E. Harris, \& P.E. Morris (Eds.), Everyday memory actions and absent-mindedness. London: Academic Press.

Hersh, N.A. \& Treadgold, L.G. (1994). Neuropage: The rehabilitation of memory dysfunction by prosthetic memory and cueing. Neurorehabilitation, 4, 187-197.

Hickox, A., \& Sunderland, A. (1992). Questionnaire and checklist approaches to assessment of everyday memory problems. In J.R. Crawford, D.M. Parker \& W.W. McKinlay (Eds.), A handbook of neuropsychological assessment. Hillsdale: Erlbaum.

Hutchinson, J., \& Marquardt, T.P. (1997). Functional treatment approaches to memory impairment following brain injury. Topics in Language Disorders, 18, 45-57.

Kim, H.J., Burke, D.T., Dowds, M.M., \& George, J. (1999). Utility of a microcomputer as an external memory aid for a memory-impaired head injury patient during in-patient rehabilitation. Brain Injury, 13, 147-150. 
Kim, H.J., Burke, D.T., Dowds, M.M., Jr., Robinson Boone, K.A., \& Park, G.J. (2000). Electronic memory aids for outpatient brain injury: follow-up findings. Brain Injury, 14, 187-196.

Kinsella, G., Murtagh, D., Landry, A., Homfray, K., Hammind, M., O'Beirne, L., Dwyer, L., Lamont, M., \& Ponsford, J. (1996). Everyday memory following traumatic brain injury. Brain Injury, 10, 499-507.

Klonoff, P.S., O’Brien, K.P., Prigatano, G.P., Chiapello, D.A., \& Cunningham, M. (1989). Cognitive retraining after traumatic brain injury and its role in facilitating awareness. Journal of Head Trauma Rehabilitation, 4, 37-45.

Kotler-Cope, S. \& Camp, C.J. (1990). Memory interventions in aging populations. In E.A. Lovelace (Eds.), Aging and cognition: Mental processes, self awareness and interventions. North Holland: Elsevier Science Publishers.

Levin, H.S., \& Goldstein, F.C. (1986). Organization of verbal memory after severe closed-head injury. Journal of Clinical and Experimental Neuropsychology, 8, 643-656.

Levin, H.S. (1991). Memory deficits after closed head injury. In F. Boller \& J. Grafman (Eds.), Handbook of neuropsychology (Vol. 6). Amsterdam: Elsevier.

Lynch, W.J. (1995). You must remember this: Assistive devices for memory impairment. Journal of Head Trauma Rehabilitation, 10, 94-97.

Makatura, T.J., Lam, C.S., Leahy, B.J., Castillo, M.T., \& Kalpakjian, C.Z. (1999). Standardised memory tests and the appraisal of everyday memory. Brain Injury, 13, 355-367.

Mangels, J., Craik, F., Levine, B., Schwartz, M., \& Stuss, D. (2000). Chronic deficits in item and context memory following traumatic brain injury: A function of attention and injury severity. Brain and Cognition, 44, 107-112.

Mateer, C.A., Sohlberg, M.M., \& Crinean, J. (1987). Focus on clinical research: Perceptions of memory function in individuals with closed-head injury. Journal of Head Trauma Rehabilitation, 2, 74-84.

Maylor, E. A., (1998). Changes in event-based prospective memory across adulthood. Aging, Neuropsychology and Cognition, 5, 107-128.

McKitrick, L.A., Camp, C.J., \& Black, F.W. (1992). Prospective memory intervention in Alzheimer's disease. Journal of Gerontology: Psychological Sciences, 47, 337-343.

Millis, S.R., \& Dijkers, M. (1993). Use of the Recognition Memory Test in traumatic brain injury: Preliminary findings. Brain Injury, 7, 53-58.

Mills, V., Kixmiller, J.S., Gillespie, A., Allard, J., Flynn, E., Bowman, A., \& Brawn, C.M. (1997). The correspondence between the Rivermead Behavioural Memory Test and ecological prospective memory. Brain and Cognition, 35, 322-325.

Otani, H., Landau, J.D., Libkuman, T.M., St Louis, J.P., Kazen, J.K., \& Throne, G.W. (1997). Prospective memory and divided attention. Memory, 5, 343-360.
Ownsworth, T.L. \& McFarland, K. (1999). Memory remediation in long-term acquired brain injury: Two approaches in diary training. Brain Injury, 13, 605-626.

Ownsworth, T.L., McFarland, K.M., \& Young, R.M. (2000). Development and standardization of the Self-regulation Skills Interview (SRSI): a new clinical assessment tool for acquired brain injury. Clinical Neuropsychologist, 14, 76-92.

Ponsford, J. (1995). Mechanisms, recovery, and sequelae of traumatic brain injury: A foundation for the REAL approach. In J. Ponsford, S. Sloan \& P. Snow (Eds.), Traumatic brain injury: Rehabilitation for everyday adaptive living. Hove: Erlbaum.

Raskin, S.A., \& Buckheit, C.A. (2000). Memory for Intentions Screening Test. Unpublished test.

Raskin, S.A., \& Sohlberg, M.M. (1996). The efficacy of prospective memory training in two adults with brain injury. Journal of Head Trauma Rehabilitation, 11, 32-51.

Raymond, M.J., Malia, K.B., Bewick, K.C., \& Bennett, T.L. (1996). A comprehensive approach to memory rehabilitation following brain injury. The Journal of Cognitive Rehabilitation, 14, 18-23.

Reid, D.B., \& Kelly, M.P. (1993). Wechsler Memory Scale-Revised in closed head injury. Journal of Clinical Psychology, 49, 245-254.

Richardson, J.T.E. (2000). Clinical and neuropsychological aspects of closed head injury (3rd ed.). London: Taylor \& Francis.

Roche, N.L., Fleming, J.M., \& Shum, D.H.K. (2001). Self-awareness of prospective memory failure in adults with traumatic brain injury. Manuscript submitted for publication.

Schmitter-Edgecombe, M., Fahy, J.F., Whelan, J.P., \& Long, C.J. (1995). Memory remediation after severe closed head injury: notebook training versus supportive therapy. Journal of Consulting and Clinical Psychology, 63, 484-489.

Schwartz, A.F., \& McMillan, T.M. (1989). Assessment of everyday memory after severe head injury. Cortex, 25, 665-671.

Sellen, A.J., Louie, G., Harris, J.E., \& Wilkins, A.J. (1997). What brings intentions to mind? An in situ study of prospective memory. Memory, 5, 483-507.

Shum, D.H.K., Harris, D., \& O'Gorman, J.G. (2000). Effects of severe traumatic brain injury on visual memory. Journal of Clinical and Experimental Neuropsychology, 22, 25-39.

Shum, D., Sweeper, S., \& Murray, R. (1996). Performance on verbal implicit and explicit memory tasks following traumatic brain injury. Journal of Head Trauma Rehabilitation, 11, 43-53.

Shum, D., Valentine, M., \& Cutmore, T. (1999). Performance of individuals with severe long-term traumatic brain-injury on time-, event-, and activitybased prospective memory tasks. Journal of Clinical and Experimental Neuropsychology, 21, 49-58. 
Sohlberg, M.M. \& Mateer, C.A. (1989a). Introduction to cognitive rehabilitation: Theory and practice. New York: Guilford Press.

Sohlberg, M.M. \& Mateer, C.A. (1989b). Training use of compensatory memory books: A three stage behavioral approach. Journal of Clinical and Experimental Neuropsychology, 11, 871-891.

Sohlberg, M.M., \& Raskin, S.A. (1996). Principles of generalization applied to attention and memory interventions. Journal of Head Trauma Rehabilitation, 11, 65-78.

Sohlberg, M.M., White, O., Evans, E., \& Mateer, C. (1992a). Background and initial case studies into the effects of prospective memory training. Brain Injury, 6, 129-138.

Sohlberg, M.M., White, O., Evans, E., \& Mateer, C. (1992b). An investigation of the effects of prospective memory training. Brain Injury, 6, 139-154.

Sunderland, A., Harris, J.E., \& Baddeley, A.D. (1983). Do laboratory tests predict everyday memory? A neuropsychological study. Journal of Verbal Learning and Verbal Behavior, 22, 341-357.

Sunderland, A., Harris, J.E., \& Gleave, J. (1984). Memory failures in everyday life following severe head injury. Journal of Clinical Neuropsychology, 6, 127-142.

Tate, R.L. (1997). Beyond one-bun, two-shoe: recent advances in the psychological rehabilitation of memory disorders after acquired brain injury. Brain Injury, 11, 907-918.

Thompson, S.B.N. (1996). Practical ways of improving memory storage and retrieval problems in-patients with head injuries. British Journal of Occupational Therapy, 59, 418-422.

Titov, N., \& Knight, R.G. (2000). A procedure for testing prospective remembering in persons with neurological impairments. Brain Injury, 14, 877-886.

Titov, N., \& Knight, R.G. (2001). A video-based procedure for the assessment of prospective memory. Applied Cognitive Psychology, 15, 61-83.

Unsworth, C. (1999). Introduction to cognitive and perceptual dysfunction: Theoretical approaches to therapy. In C. Unsworth (Ed), Cognitive and perceptual dysfunction. Philadelphia: F.A. Davis.

Van den Broek, M.D., Downes, J., Johnson, Z., Dayus, B., \& Hilton, N. (2000). Evaluation of an electronic memory aid in the neuropsychological rehabilitation of prospective memory deficits. Brain Injury, $14,455-462$.

Vanderploeg, R.D., Crowell, T.A., \& Curtiss, G. (2001). Verbal learning and memory deficits in traumatic brain injury: encoding, consolidation, and retrieval. Journal of Clinical and Experimental Neuropsychology, 23, 185-95.

Vortac, O.U., Edwards, M.B., \& Manning, C.A. (1995). Functions of external cues in prospective memory. Memory, 3, 201-219.

Waugh, N. (1999). Self-report of the young, middle-aged, young-old and old-old individuals on prospective memory functioning. Unpublished honours thesis, Griffith University, Brisbane, Queensland, Australia.

Williamson, D.J.G., Scott, J.G., \& Adams, R.L. (1996). Traumatic brain injury. In R.L. Adams, O.A. Parsons, J.L. Culbertson, \& S.J. Nixon (Eds), Neuropsychology for clinical practice: Etiology, assessment, and treatment of common neurological disorder. Washington DC: American Psychological Association.

Wills, P., Clare, L., Shiel, A., \& Wilson, B.A. (2000). Assessing subtle memory impairments in the everyday memory performance of brain injured people: Exploring the potential of the Extended Rivermead Behavioural Memory Test. Brain Injury, 14, 693-704.

Wilson, B.A. \& Evans, J. The Cambridge Behavioural Prospective Memory Test. Unpublished test.

Wilson, B.A. (1992). Memory therapy in practice. In B.A. Wilson \& N. Moffat (Eds.), Clinical Management of Memory Problems (2nd ed.). London: Chapman \& Hall.

Wilson, B.A. (1995). Management and remediation of memory problems in brain-injured adults. In A.D. Baddeley, B.A. Wilson \& F.N. Watts (Eds), Handbook of memory disorders. Chichester: John Wiley \& Sons.

Wilson, B.A. (1999). Memory rehabilitation in braininjured people. In D.T. Stuss, G. Winocur \& I.H. Robertson (Eds.), Cognitive neurorehabilitation. New York: Cambridge University Press.

Winograd, E. (1988). Some observations on prospective remembering. In M.M. Gruneberg, P.E. Morris \& R.N. Sykes (Eds.), Practical aspects of memory: Current research and issues, vol. 1: Memory in everyday life. Chichester: John Wiley \& Sons.

Wiseman, K.A., Ratcliff, G., Chase, S., Laporte, D.L., Robertson, D.U., \& Colantonio, A. (2000). Does a test of functional memory during the post-acute period predict long-term outcome of traumatic brain injury? Brain and Cognition, 44, 14-18.

Zencius, A., Wesolowski, M.D., Krankowski, T., \& Burke, W.H. (1991). Memory notebook training with traumatically brain injured clients. Brain Injury, $5,321-325$. 